\title{
On some extensions to Lee's retrospect and prospect IS paper
}

\author{
Mats Lundeberg \\ Stockholm School of Economics, Stockholm, Sweden \\ Journal of Information Technology (2010) 25, 349. doi:10.1057/jit.2010.26
}

I have read with great interest Allen S. Lee's content-rich and thought-provoking retrospect and prospect IS paper. The perspective I have taken in reading the paper has been as a member of the IS research community ('a native') especially interested in the question of how to do research. In his paper, Lee takes, as his opening premise, the necessity for reengineering the IS research enterprise. In the retrospect part, he explores the distinction between 'theories in use' and 'espoused theories' for key concepts such as 'information', 'system', 'theory', 'organization' and 'relevance'. In the prospect part, he charts a course for the future development of the IS research discipline modeled on research disciplines found in professions such as medicine, engineering, architecture and law.

Lee has in earlier papers argued for the importance of qualitative research and design research and for their being just as valid as statistical hypothesis-testing research. In an elegant manner, he has argued that it is not a question of either - or but rather of both - and. The spirit has thus been to accept statistical hypothesis-testing research where suitable, and supplement with qualitative research and design research where appropriate.

In thinking about how to extend Lee's discussion in different possible directions I have found such a supplementary approach appealing. Inspired by Lee I will use a similar approach here. I start from Lee's paper as it stands and ask where the discussion could be extended. With my perspective described above, the focus will be on extensions of how to do research: (1) Problematizing 'theories in use' and 'espoused theories'; (2) Balancing prescriptions and general direction; (3) Working with different levels of abstraction.

Problematizing 'theories in use' and 'espoused theories'. Lee argues forcefully for distinguishing between 'theories in use' and 'espoused theories' and points to detrimental consequences that can follow from the variance between the two. I quite agree that such distinctions are important. However, for me, it is very difficult to achieve a situation where my 'theories in use' and 'espoused theories' are identical. It is inherently difficult to reach such uniformity. An example from Lee's paper can help illustrate my point.
Lee states that his essay takes, as its opening premise, the necessity for reengineering the IS research enterprise ('Lee's espoused theory'). In the paper, reengineering activities are not commented on very much, but instead 'theories in use' and 'espoused theories' are elaborated extensively ('Lee's theory in use'). In conclusion, I agree about the importance of the distinction between 'theories in use' and 'espoused theories' but would suggest that the discussion is supplemented with how to tackle some of the difficulties. It seems as if we have to find ways of living with variance between the two.

Balancing prescriptions and general direction. In the prospect part, Lee offers prescriptions involving each of the five key facets of IS research - 'information', 'system', 'theory', 'organization' and 'relevance' - and suggests a general direction for the development of the academic discipline of IS - modeled on research disciplines found in professions such as medicine, engineering, architecture and law. The prescriptions as well as the general direction are interesting as such. I would suggest they are supplemented with a discussion of the relationship between the prescriptions and the general direction. Specifically, how have such prescriptions helped the above professions remedy problems caused by differences between their disciplines' espoused theories and theories-in-use about how to do research? Such a discussion could give a more balanced view of how to proceed in our field.

Working with different levels of abstraction. As stated above, the paper seems to have a difference between an espoused theory of Lee's ('The necessity for reengineering the IS research enterprise') and a theory-in-use of Lee's ("Minimize the variance between "theories in use" and "espoused theories"'). These two theories are not necessarily contradictory. They are just on different levels of abstraction. Minimizing the variance can be seen as means to the end of reengineering the IS research enterprise. Combining different levels of abstraction can help us obtain a richer picture of the situation in focus and in this manner supplement existing levels. Enhancing our ability to work with and combine different levels of abstraction seems to be an important part of the next 25 years of IS research. 